\title{
Rhythm of life: choices, challenges and change
}

\author{
Rob Lake \\ Positive Life NSW \\ Email: robl@positivelife.org.au
}

Life with human immunodeficiency virus (HIV) in 2010 is life with a future, a different situation to that in 1989 or even 1999. Conclusive evidence of the success of combination antiretroviral therapy was first presented at the 1996 World AIDS Conference. Subsequent treatments and combinations of treatments have, for most people with HIV, achieved better results. These improved treatment outcomes translate as the achievement and long-term maintenance of undetectable HIV viral load, greatly increased CD4 cell counts and fewer side-effects from therapy.

For people with HIV like me, treatment consists of twicedaily tablets and regular monitoring, a bit too much time in hospital pharmacies and more optimism about my future health than in 1995 when I was first diagnosed. Life with HIV for me is about work, family, friends, good health and wellbeing. I am lucky that I can be open about my HIV status at home, at work and to family: many people are not so fortunate as demonstrated by $57 \%$ of respondents to Futures 6 reporting that they had not disclosed their HIV status to their employers. ${ }^{1}$

My experience differs from that of other men and women, particularly older people, who have lived long-term with HIV. Their experience is tempered by: unpredictable, uncertain interactions between the impacts of HIV on the body; the premature experience of ageing-related health; physiological and sometimes cognitive impairments; and the psychosocial impact of long-term debilitating illness.

Poverty and social exclusion are recognised as important social determinants of health. Discrimination and stigma arise from judgmental attitudes about HIV and how it is acquired, homophobia, and fear of transmission. Women and men with HIV experience this discrimination: in the workplace; among family and other relationships; and from health-care providers. It has been identified through research including the Futures studies and Men and Women Living Heterosexually with HIV. ${ }^{1,2}$
To be optimistic about future health and wellbeing for people with HIV we need: ongoing improvements to treatments; the uptake and availability of these treatments; and a better understanding of the impact and management of co-infections and the implications of mental illness and heart, kidney and similar diseases. People with HIV, including those who migrate to Australia, need to be included, valued citizens. Those with the highest need must be assisted with clinical and other support services to ensure early interventions and comprehensive, coordinated care, some of which will be HIV specific. They also need services such as aged care, oncology and treatment for other conditions. The contemporary experience of HIV diagnosis now incorporates improved treatment outcomes and reduced side-effects from treatment. Timely access to relevant support and information continues to be a key factor in determining how well someone integrates HIV into their life.

HIV prevention has two aspects for us:

- preventing transmission

- and better health for people with HIV through the good management of HIV-related and preventable conditions.

Individually and as part of HIV organisations, we have a role to play. We share a responsibility to prevent HIV transmission, to care for ourselves, our partners and our communities in the same way we expect them to care for us. That care includes identifying and addressing stigma and discrimination.

This is a time for reflection, a time to prepare for the future with the goal of achieving the best possible health and quality of life for women and men with HIV. It's a future some didn't think they'd see and it's worth fighting for.

\section{References}

1. Grierson J, Power J, Pitts M, Croy S, Clement T, Thorpe R et al. HIV Futures 6: Making positive lives count, Monograph series number 74. Melbourne: Australian Research Centre in Sex, Health and Society, Latrobe University; 2009.

2. Persson A, Richards W, Barton D, Reakes K. Men and women living heterosexually with HIV: the Straightpoz Study. Volume 2 (Monograph 1/2009). Sydney: National Centre in HIV Social Research, The University of New South Wales; 2009. 